\section{Tardigrades and Microscopes}

William R. Miller

Chestnut Hill College, Philadelphia, PA millerw@chc.edu

Commonly known as 'water bears', tardigrades are a phylum of microscopic animals that can be found living on mosses and lichens all over the world. The name Tardigrada means 'slow walker' which describes their sluggish, deliberate movements. Between these slow movements and their 'teddy bear' like appearance, tardigrades are the only really "cute" invertebrate.

Tardigrades, Echiniscus sp., are generally less than 500 micrometers in length and require at least 40-power magnification to be seen clearly. They are actually aquatic invertebrates that live in the drops of water found trapped between the leaves of mosses, the thalli of lichens, grains of sand on a beach, in leaf litter, in soil, or marine sediments. They are free living and found almost everywhere. The lichen on the side of your nearest tree is a good place to find them.

The tardigrades are simple caterpillar looking animals with four pair of unjointed legs, each ending in multiple claws. They are characterized by having five visible body segments, a brain, ventral nervous system, and well developed muscles. Water-

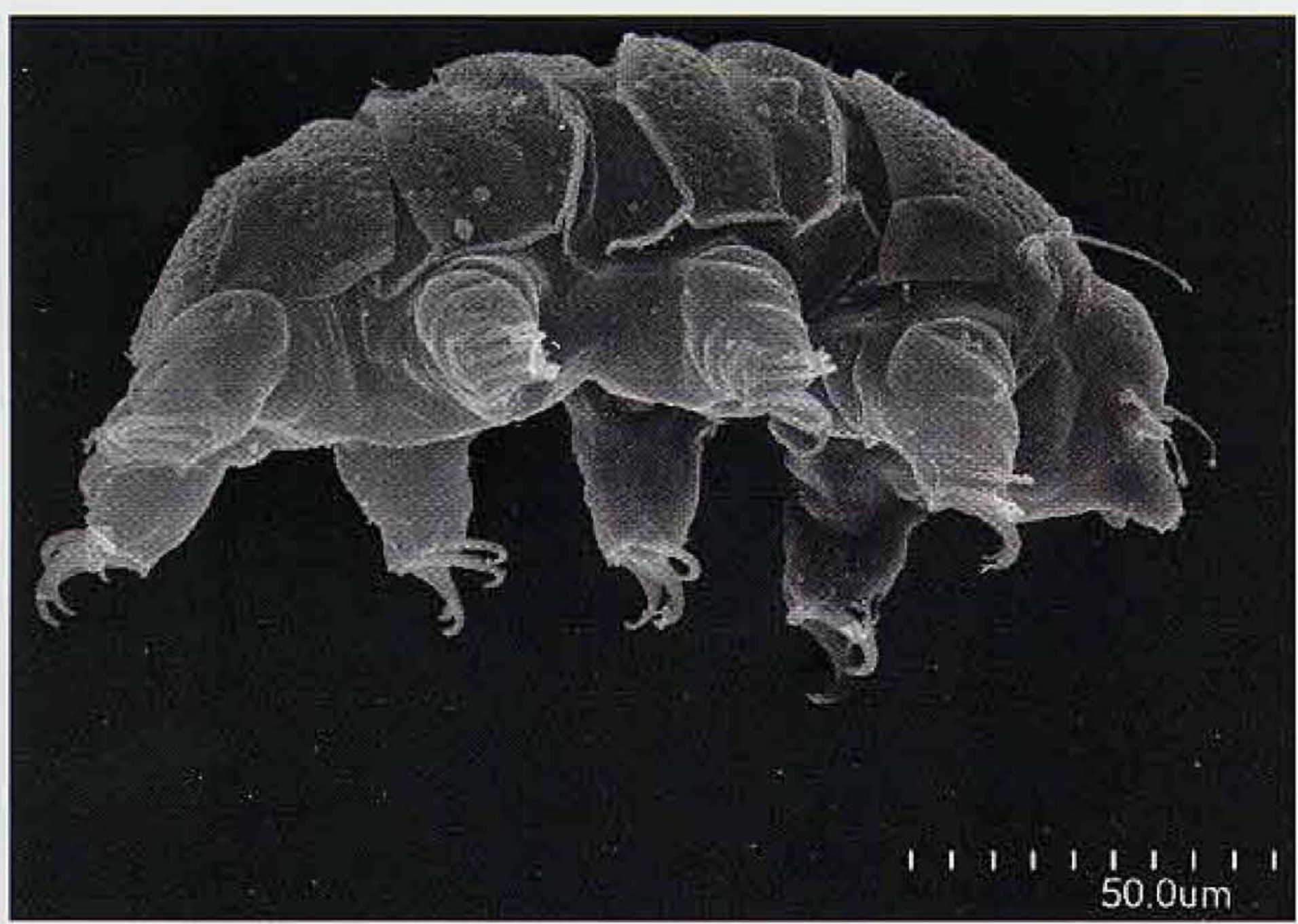

bears have a complete digestive system including a mouth with sharp stylets for piercing food, a muscular pharynx for sucking out the nutrients, an intestine for digestion, and exit anus. Some tardigrades have separate sexes and lay spectacularly ornate eggs, some are hermaphroditic, while others are parthenogentic. All members of the phylum lack a respiratory system and absorb oxygen through their cuticle and or gut. Likewise, they lack a circulatory system and use their hemocoel for circulation of nutriments, oxygen, and waste removal.

While tardigrades are found in marine, freshwater, and terrestrial environments, it is the continental species that live in water droplets on land plants that have made the group famous or at least interesting. Terrestrial tardigrades exhibit "cryptobiosis", a reversible suspension of metabolism set in motion by the environment. They desiccate as the environment dries out, shrivel to about $1 / 3$ adult size, form a resistant state called a "tun", and wait for moisture to return to become active again. In cryptobiosis, tardigrades can survive extreme environmental conditions for long periods of time. Experimentally, they have survived exposure to $0.05^{\circ}$ Kelvin for almost a full day and mi- nus $200^{\circ}$ centigrade for almost two years, they have tolerated temperatures above the boiling point, and returned to the active state after exposure to 6000 atmospheres of pressure and high vacuums. Multi-year survival of cryptobiotic tardigrades is not uncommon and there is some evidence to suggest it may exceed a century. Some authors have speculated that tardigrades could survive space travel.

Over 750 species of tardigrades have been described. The higher taxonomy is based on the presence, absence, size or shape of its external features such as cuticle, pores, body plates, spines, and claws. The identification to species generally requires the observation, measurement, and counting of internal structures such as mouthparts which are observable with a light microscope. The adults of a few species are so similar that it is necessary to use the projections found on the eggs to determine species. There is no current, complete monograph available.

Terrestrial tardigrades are easily collected by grabbing a hand full of moss or scraping a bit of lichen into a small paper bag or envelope. In the laboratory, the sample is submerged in a bowl of spring water and allowed to sit for 24 hours. The plant material may be removed, squeezed and discarded. Tardigrades will be found crawling about among the debris on the bottom of the bowl. Pipetting a sub-sample into a small petri dish, and examining it over a black background at $40 \mathrm{X}$ with a dissecting or stereo-zoom microscope with reflected light is the best technique to observe them. A fiber optic, flexible tube seems to work best as a light source.

For quick observation, make a water mount slide. A cavity slide is generally not necessary. Water mounts may be used up to $400 \mathrm{X}$ and even on student scopes. Tardigrades in water will be slightly compressed by the cover slip but will demonstrate their internal functions including the use of their stylets, muscles, leg \& claw movement, digestive activity, and the movement of body cavity cells. This is a great level for student observations and classroom lab projects.

For permanent slides, we use Hoyer's media, which has the great property that the animal can be inserted directly from the environment or a preservative. The advantage of Hoyer's is that it acts as a clearing agent, turns the critters functionally transparent, makes the harder parts generally more visible and measurable. The disadvantage of Hoyer's is that it continues to clear and in time the specimen may disappear altogether. This

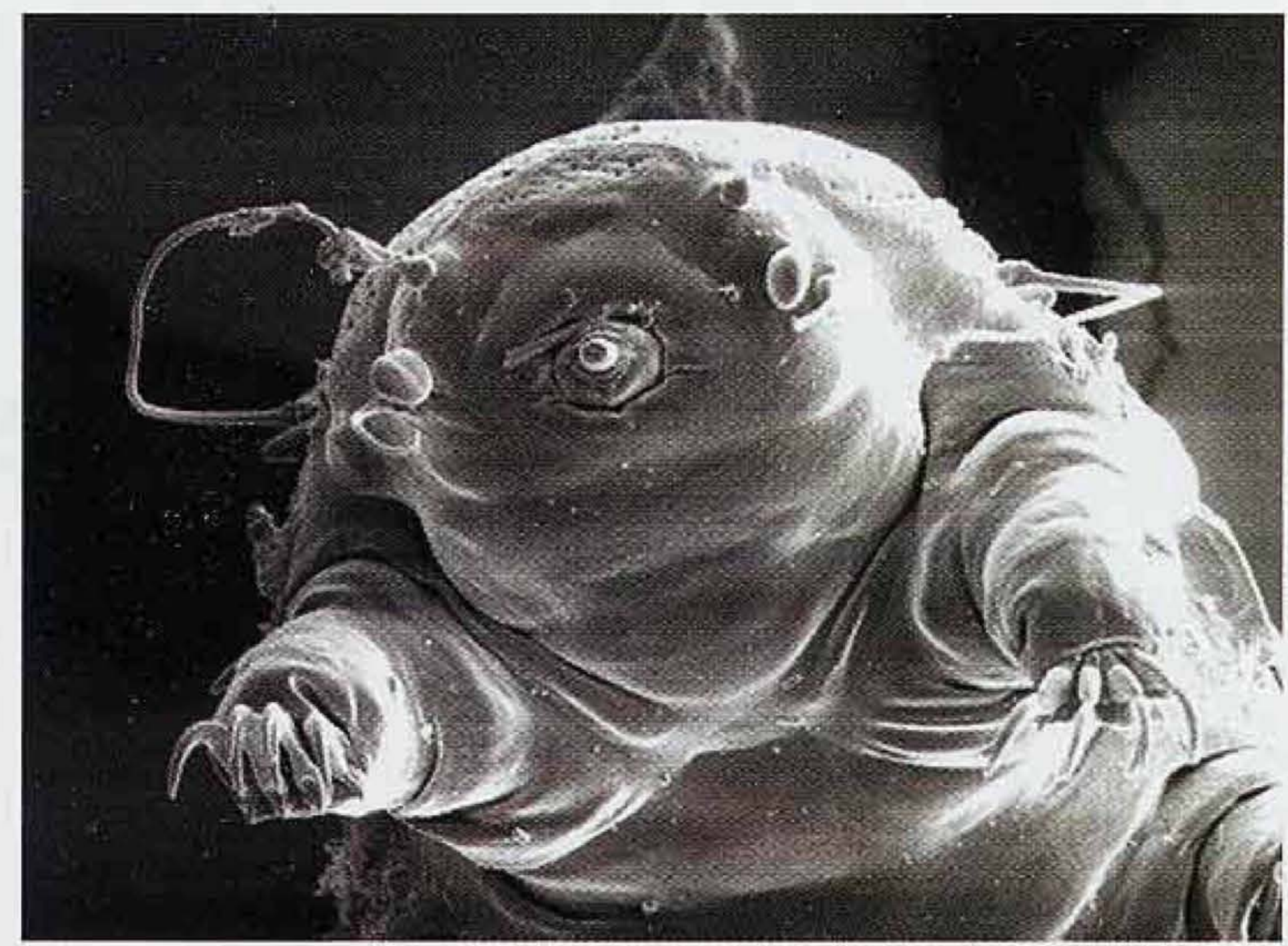




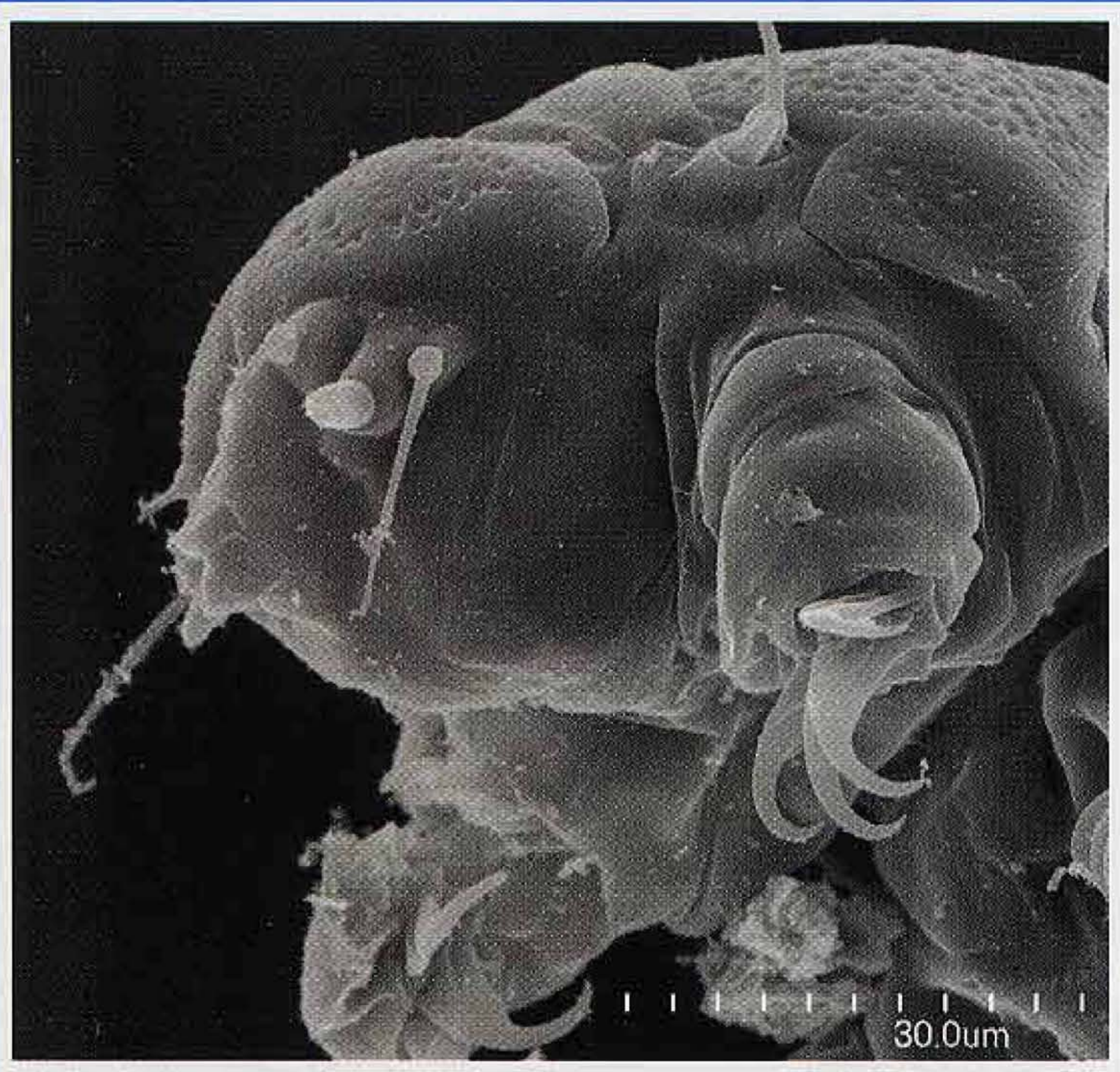

is a problem that has no current answer. Some researchers are experimenting with poly-vinyl lactophenol and poly-vinyl alcohol as mounting media, but we have no longevity data on these media and tardigrades. We are always open for ideas.

Tardigrades are easily observed with light microscopy. A few workers have developed dark field and polarized techniques but most serious researchers use phase contrast microscopes including oil immersion for general work. We tend to go to differential interference contrast (DIC) to take pictures necessary for publication. The microscopy challenge is that tardigrades are a very three-dimensional specimen even under a cover slip, thus the position of a specimen is critical to the structures that can be seen. Often it is necessary to use two or three specimens in different positions to be able to see all the structures necessary for identification.

One of the pleasures of working with tardigrades is occasionally being able to use a Scanning Electron Microscope (SEM) to create spectacular images of these fantastic creatures. Their body shape, claws, and legs give them an out of this world aura that viewers seem to like. Because of the high cost, specialized installation, and relative unavailability of SEM, it is not used to select minute structures for identification to species. SEM is best used to supplement, understand, and comprehend the structures visible under the light microscopes. SEM pictures often amplify and provide the three-dimensional vision of the relationships of structures.

Tardigrades are studied as a labor of love, because it is difficult to generate funding for an animal that is not harmful to humans and generally considered to lack economic and ecological importance. We do not like being lumped and labeled as "minor phyla" or "lesser Protostomes," but we do accept that Tardigrades are a "lesser known" phyla.

There are about a dozen people in the world who work on tardigrades. But nobody gets paid to study them. We have held an international symposium every 3 years for the last quarter century. The last was in Copenhagen in 2000 and the next will be in Tampa, Florida in 2003. For more information contact the author.

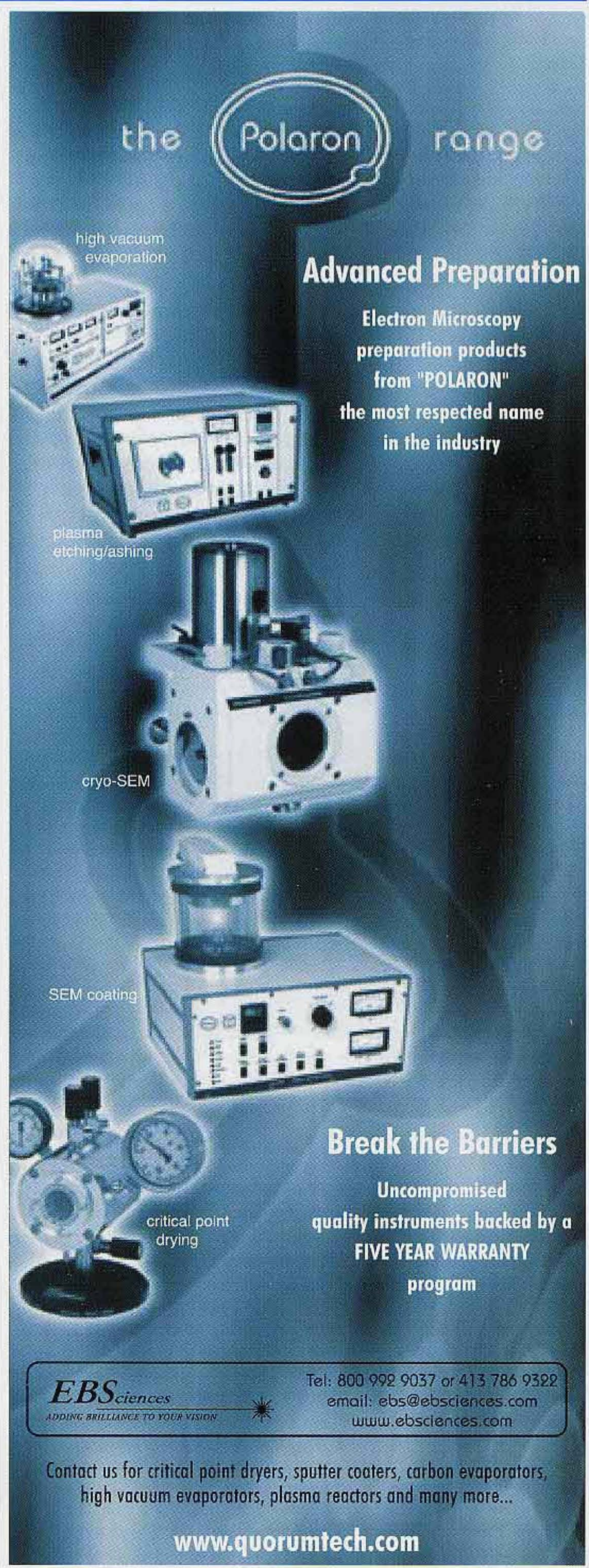




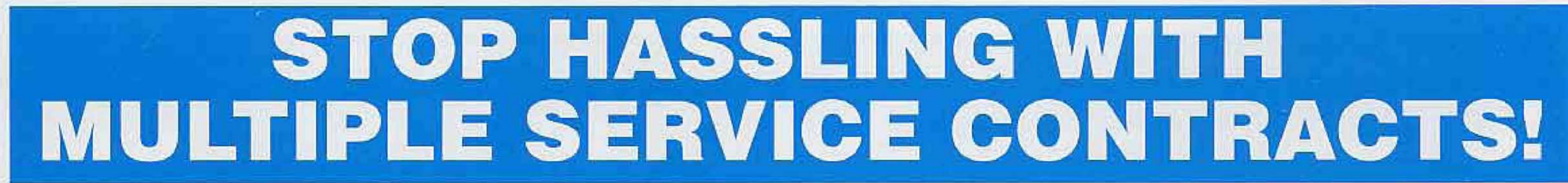

START by putting all of your instruments under one service contract with MAS (regardless of make or model). Our expert EM SERVICE GROUP has the knowledge and skills to keep your instrument working at its best.

\section{TEM'S / SEM'S PREP EQUIPMENT SPECIAL SERVIGES}

HITACHI TOPCON VACUUM COATERS

JEOL ISI

AMRAY CAMBRIDGE
PLASMA ASHERS

SPUTTER COATERS

ION MILLS
STAGES

BEAM BLANKERS

CUSTOM DEVICES
NEW NEW NEW

\section{Authorized service representatives} for Gatan preparation equipment and Topcon TEM'S.
Contracts and On-Demand

Emergency Service at

Reasonable Rates from

Factory Trained Specialists.

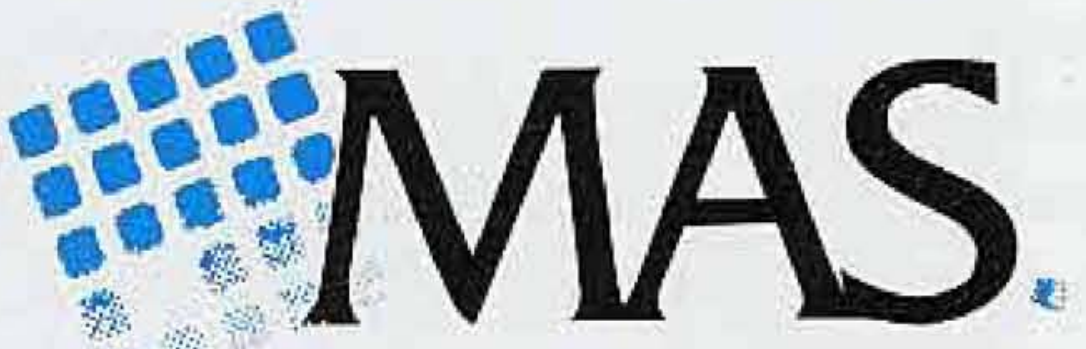

800-421-8451

3945 Lakefield Court Suwanee, Georgia 30024 770-866-3200 FAX 770-866-3259

616 Hutton Street Suite 101 Raleigh, North Carolina 27606 919-829-7041 FAX 919-829-5518 ADVANCED ANALYTICAL PRODUCTS AND SERVICES

\section{SERPETRENIX}

PHINE/FAX

\section{Introducing the Max View Plus}

\section{Digital Camera Attachment System}

The MaxView Plus kit includes adapters to fit microscopes \& optical devices with any of the following attachments;

C-Mount, C/S-Mount, T-Mount, $23 \mathrm{~mm}$ Eyepiece Port,

$30 \mathrm{~mm}$ Eyepiece Port, and 1.25" Eyepiece Ports

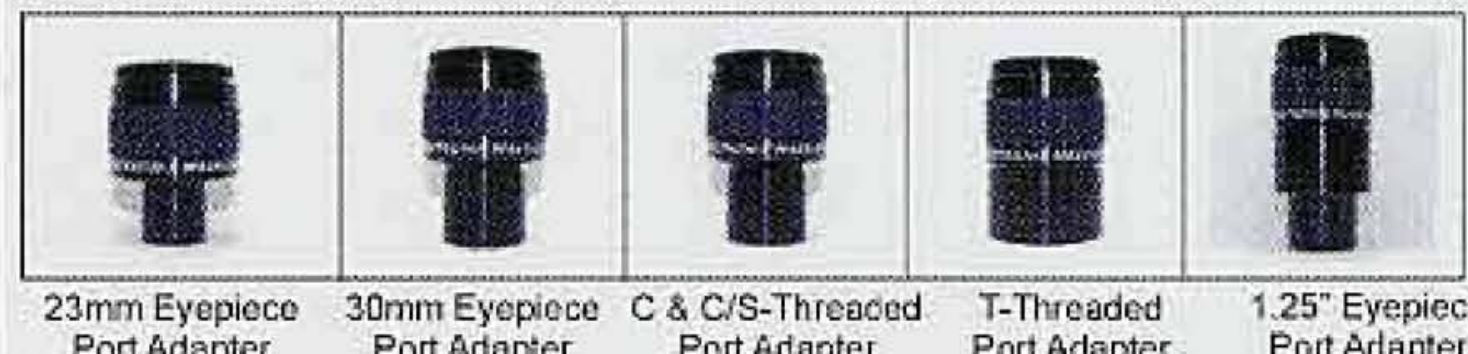

The Maxview Plus can also be used as a high quality wide angle eyepiece with the included thread-on eyeguard. The Maxview Plus is "T" threaded on top so you will need the appropriate Attachment Kit to mate it to your particular digital camera. We carry dozens of attachment kits to fit most all popular digital cameras and we update them regularly so your MaxView Plus will not become obsolete when it is time to upgrade to a new camera If using it with a $35 \mathrm{~mm}$ SLR you will need the appropriate T-Ring for your brand of camera.

\section{onderrat}

The heart of the Maxview system. A wide field $40 \mathrm{~mm}$ ocal length four element symmetrical (Plossl) lens assembly specially mounted in a carefully designed custom cell. The lens is mounted only $1 \mathrm{~mm}$ from the top to maintain the close coupling required to reduce vignetting. The cell features a unique sliding collar assembly which serves several important function it allows quick and easy removal of the camera, it allows you to adjust eyeguard height for easy visual use, allows you to adjust magnification when used with a $35 \mathrm{~mm}$ camera, and allows you to adjust hans position to minimize vignetting with a digital camera.

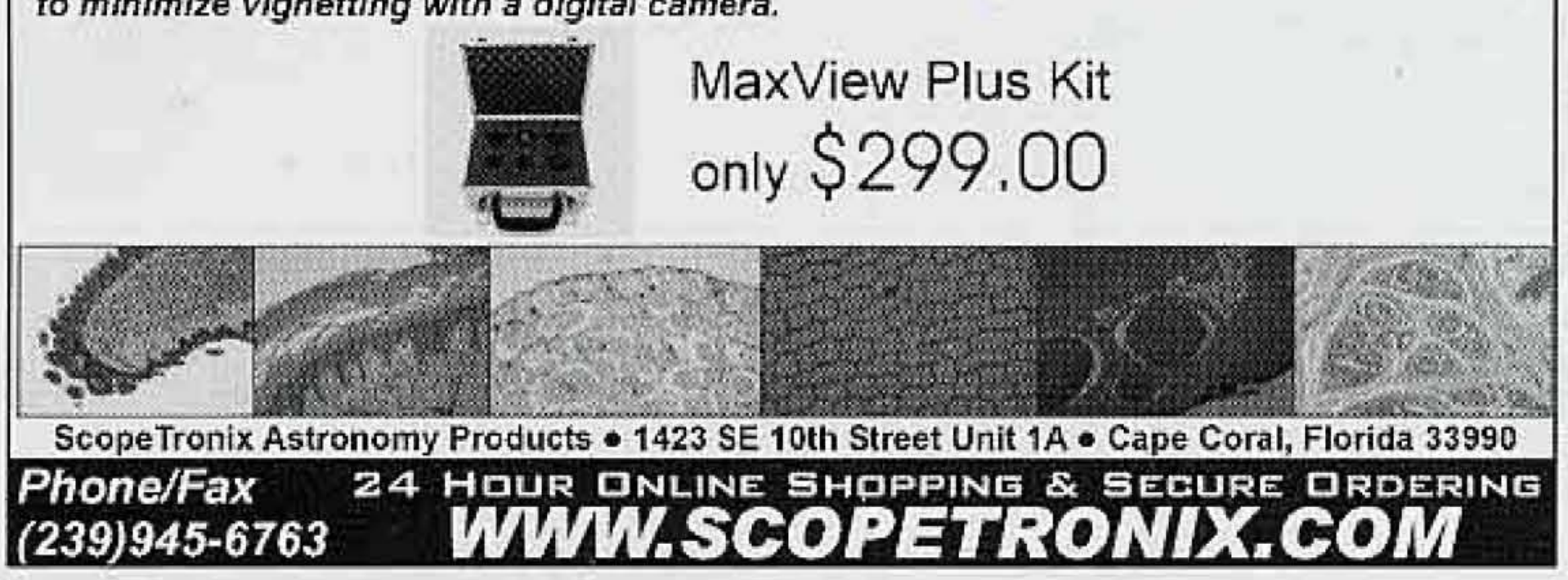

\section{NORTHERN}

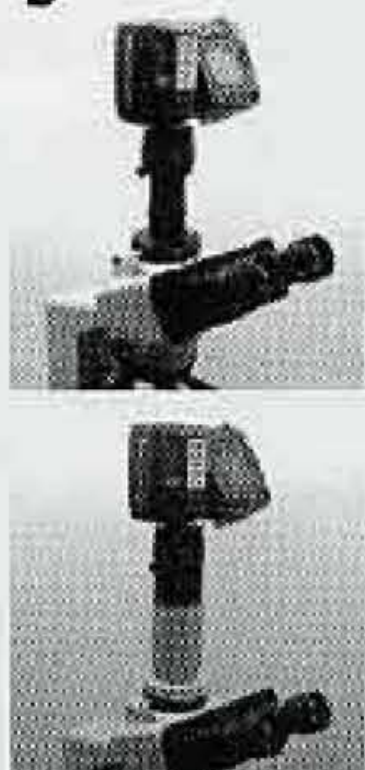

LIMTED TIME OFFER

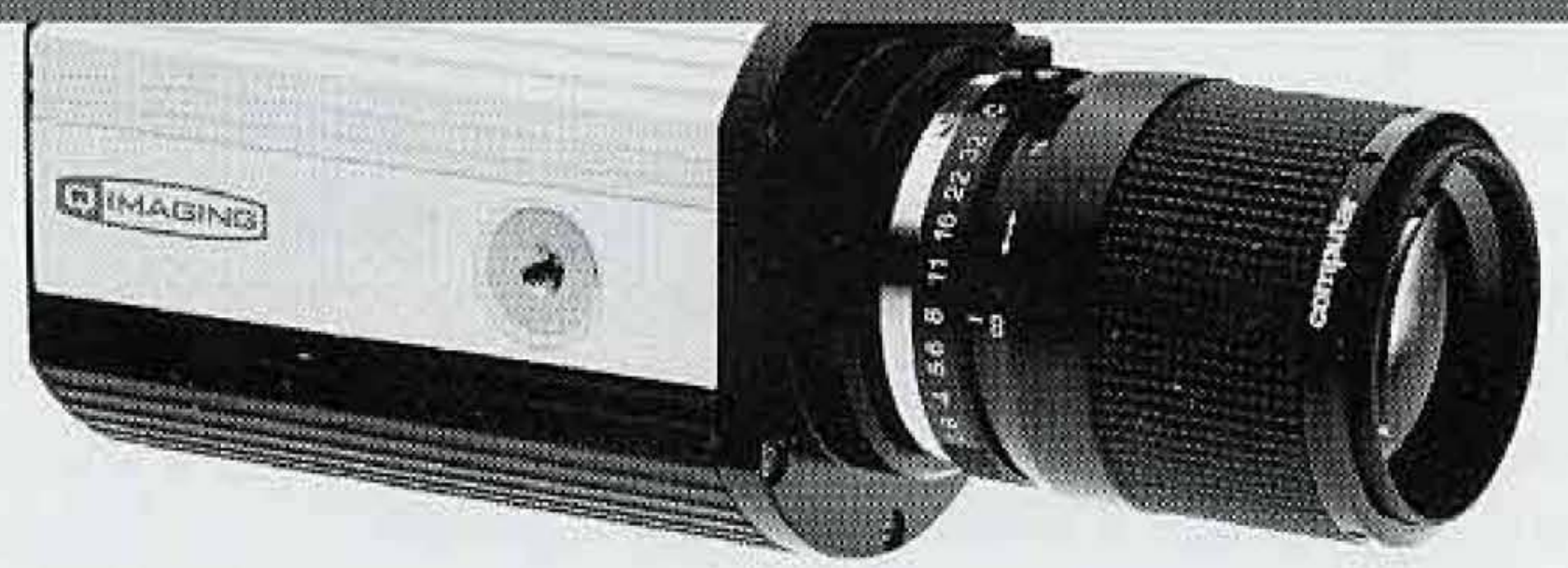

Get the power of Northern Eclipse 6.0 FREE by ordering a QImaging FireWire CCD camera When you buy a QImaging CCD FireWire camera directly from us at the manufacturer's suggested list price, we will include, for a limited time, one FREE Northern Eclipse 6.0 application of your choice. Applications such as Brightness/ Time, Time-Lapse, Image Merging, Fast Capture to Ram, and even De-convolution are available. See the On Sale page of our web site for a full list of applications available with this offer. www.empix.com

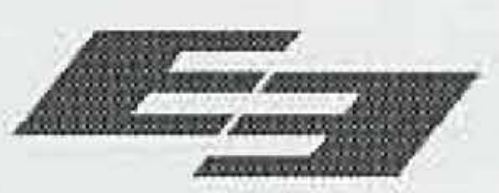

$E M P I X$ 